\title{
Laboreal
}

Volume $16 \mathrm{~N}^{\circ} 2$ | 2020

Programa de Pesquisa do Curso da Ação

\section{Impactos da pneumónica no mundo do trabalho : uma visão a partir de periódicos (1918-19)}

Impactos de la Pneumónica en el mundo del trabajo : una visión desde los periódicos (1918-19)

\section{Maria da Luz Sampaio}

\section{(2) OpenEdition}

\section{Journals}

\section{Edição electrónica}

URL: http://journals.openedition.org/laboreal/17417

DOI: $10.4000 /$ laboreal. 17417

ISSN: 1646-5237

\section{Editora}

Universidade do Porto

\section{Refêrencia eletrónica}

Maria da Luz Sampaio, «Impactos da pneumónica no mundo do trabalho : uma visão a partir de periódicos (1918-19) », Laboreal [Online], Volume 16 №2 | 2020, posto online no dia 01 dezembro 2020, consultado o 13 dezembro 2020. URL : http://journals.openedition.org/laboreal/17417 ; DOI : https://doi.org/10.4000/laboreal.17417

Este documento foi criado de forma automática no dia 13 dezembro 2020

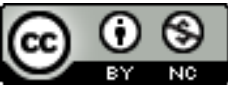

Laboreal está licenciado com uma Licença Creative Commons - Atribuição-NãoComercial 4.0 Internacional. 


\title{
Impactos da pneumónica no mundo do trabalho : uma visão a partir de periódicos (1918-19)
}

\author{
Impactos de la Pneumónica en el mundo del trabajo : una visión desde los \\ periódicos (1918-19)
}

Maria da Luz Sampaio

\section{Prolegómenos a uma (breve) incursão na história da pneumónica}

1 Entre 1918 e 1919, a humanidade foi vítima de uma epidemia conhecida internacionalmente por Spanish Influenza ou Spanish Flue, em Portugal, por Pneumónica (ou Gripe Pneumónica). Em maio de 1918, é declarada em Espanha, espalhando-se pela europa e em poucas semanas estende-se a todos os continentes. No mesmo mês, a epidemia chegou a Portugal, atingindo em primeiro lugar as regiões fronteiriças, mas em poucos meses difunde-se nos principais centros urbanos do país. A partir de então, foi possível identificar duas vagas distintas da gripe espanhola : uma primeira, entre maio e finais de julho, que se manteve mais ou menos controlada e, uma segunda vaga, entre agosto e dezembro, que assumiu efeitos dramáticos e devastadores numa população pouco informada e com pouca premência das medidas de saúde pública, tornando inevitável uma disseminação que se mostrava implacável.

2 A este panorama, juntaram-se os surtos de tifo, de varíola, e de tuberculose, que dizimaram os mais débeis e carenciados da população. Para compreender o que as populações viveram e qual o impacto que a epidemia da pneumónica ou Influenza teve no mundo do trabalho necessitávamos de realizar uma profunda incursão nos arquivos, quer de empresas existentes à época, quer da imprensa da altura. Outra importante fonte para estes estudos seria o acesso a documentação do Ministério do Trabalho e da Previdência Social. Esta pesquisa, que carece de um levantamento e de uma análise 
exaustiva e aprofundada das fontes, apresenta neste artigo alguns dos seus resultados prévios. Ainda sem a profundidade que se desejaria, recenseamos dados sobre diferentes sectores de atividade na imprensa durante o ano de 1918, em particular nos jornais O Comércio do Porto, A Capital, o Algarve (1918-19), disponíveis na Hemeroteca Digital, a partir de uma seleção que teve por base observar as notícias produzidas em três locais do país, em três projetos editoriais distintos. Procuramos encontrar neste levantamento informação sobre a atuação de diferentes sectores de atividade durante a incidência da pneumónica, e quais os impactos sobre o mercado de trabalho e a atividade das empresas.

\section{Portugal em 1918 : a fome, a guerra e os surtos epidémicos}

3 Em 1918, Portugal era num país de feição rural, a braços com uma situação económica e financeira complexa - sofrendo o impacto do conflito mundial -, já de si suficientemente fragilizada por uma economia "dependente do comércio exterior em matéria de abastecimentos alimentares (cereais) e energéticos (carvão)” (Pires, 2018).

O armistício assinado a 11 de novembro e o fim da guerra em 1918 trouxe os soldados de volta a casa, mas a grande maioria regressou mutilado ou esgazeado, cenário a que muitas associações mutualistas tentaram dar resposta desenvolvendo campanhas de apoio. A par com esta dura realidade, a guerra tinha trazido também uma falta de muitos produtos estrangeiros e, em Portugal, para fazer face à escassez dos produtos de primeira necessidade, criou-se as Comissões de subsistências, controladas pelo poder local, pretendendo através delas assegurar o fornecimento de bens alimentares.

5 A imprensa da época registava com regularidade o papel das Comissões na distribuição de pão, açúcar, gasolina, entre outros produtos, mas, também, as irregularidades cometidas por parte de padarias, mercearias que retinham os produtos para aumentar os preços (Pires, 2018). A fome, a guerra e os surtos epidémicos serão, neste ano de 1918, uma trilogia fatal para os grupos mais vulneráveis da população.

O jornal O Comércio do Porto, em setembro de 1918, publica um artigo intitulado "A Influenza - pneumónica”, e divulga o documento que Ricardo Jorge apresentou ao Conselho Superior de Hygiene, onde se faz a história do aparecimento da Influenza que atingiu sobretudo os quartéis, focos principais da epidemia, e de onde terá saído para se disseminar de forma rápida de preferência por gente nova (...) (o Comércio do Porto 1918). E refere ainda que "não se oferece prophylaxia effectiva e eficaz a exercer contra tal epidemia que não seja a hygiene geral e assistência aos atacados, preferencialmente em Hospital de isolamento" (O Comércio do Porto, 1918).

7 Apesar dos relatórios e advertências de Ricardo Jorge, então Diretor Geral de Saúde, a realidade demonstrava a falta de estruturas organizadas junto da população para promover cuidados clínicos e reverter a disseminação do surto. A pandemia, contava, pois, com muitos fatores a seu favor: em primeiro lugar a guerra, depois a fome generalizada pela escassez de bens alimentares e medicamentos e, a agravar, a falta de condições de higiene e sanitárias das casas e bairros onde a população vivia sem água canalisada ou saneamento básico. No Porto, a imprensa registava como a população das ilhas (bairros operários), nestes locais húmidos e insalubres, eram focos da doença, dizimando facilmente, famílias inteiras. Às corporações de bombeiros competia 
incinerar as pequenas e rudimentares casas, procurando assim estancar a propagação da doença. A esta gripe juntava-se a "epidemia de tifo que incidiu em particular nas zonas do Porto e de Espinho, dizimando mais de 2000 pessoas" (Sequeira, 2001, p. 50). A 15 de outubro, face a um pico do surto epidemiológico, o mesmo jornal apresenta o impacto da pandemia em diversas zonas do norte do país, assinalando o aumento da taxa de mortalidade e, nas Notas por localidade, refere que, em "Santo Thyrso espera-se que a fábrica de fiação reabra", sentimento partilhado pelos mais afetados, sobretudo, o operariado fabril e seus encarregados.

\section{Os impactos da pandemia : entre a crise e a vontade de retoma}

Ao longo do ano de 1918, os periódicos analisados apresentam-nos a irregularidade do funcionamento de fábricas ou de serviços públicos, devido ao falecimento de industriais, ou dos longos períodos de convalescença dos funcionários. Em novembro de 1918, o semanário O Algarve refere que ainda não pode ser restabelecida "a regularidade do telégrafo-postal, principalmente os serviços de correio, porque a circulação ferro-viária se mantém sem pessoal para desempenhar vários cargos (...), pois a mortandade da epidemia e as demoradas convalescenças trazem fora dos lugares grande quantidade de funcionários" (O Algarve, 17 novembro 1918, p. 2).

9 A atividade industrial vive os impactos da doença, também por falta de matérias primas importadas, nomeadamente carvão, farinhas, algodão, entre outras, o que veio a afetar a produção e o abastecimento de produtos de primeira necessidade às populações. As notícias e os artigos de opinião revelam estarmos perante uma escassez prolongada, mas também de movimentações especulativas dos comerciantes e dos industriais, que retinham em armazém produtos para assim aumentar os preços. Em 30 de janeiro de 1919, A Capital noticia que a "Refinaria Colonial em Alcântara possui 200 toneladas de açúcar fabricado e 400 toneladas na fábrica, faltando já dependências para armazenagem de sacos cheios" (A Capital, janeiro 1919, p. 2). Um outro lado desta realidade revela-nos que a vida nas empresas se reorganizava perante a pandemia como o traduz o jornal o Algarve, com a publicação de um protesto público da Electro Moagem Lda. de Faro, contra as decisões arbitrárias cometidas pelo encarregado do celeiro municipal :

Tínhamos nessa altura todos os nossos empregados doentes, mas devido à boa vontade do nosso gerente a fábrica trabalhou-se debaixo da sua direção e no fim de 14 dias úteis tínhamos entregues ao celeiro a farinha respectiva. Fomos pessoalmente requisitar a sua Exa mais trigo daquele que tinha chegado a Faro (...). Disse-nos que a "fábrica grande" ia trabalhar e que ele se tinha comprometido a entregar a esta fábrica todo o trigo que viesse (...). Fizemos ver a sua Exa. que não desejávamos que todo o trigo nos fosse entregue, mas sim rateado na proporção da produção de cada fábrica, em harmonia com o decreto 4.638 de 13 de Junho, mas sua Exa. não se moveu e o facto é que a tal fábrica grande (...) há já perto de oito dias que tem nos seus armazéns 4 a 5 vagons de trigo para moer (...), sem que se saiba ao certo quando iniciará os trabalhos" (O Algarve, 17 de Novembro de 1918, no 556, p. 2). 
10 responsáveis na gestão de bens essenciais e a permissividade do poder local face às movimentações especulativas. Por outro lado, surgiram também outras oportunidades de negócio, como foi o caso da indústria conserveira, ou das companhias de seguros ( $\mathrm{O}$ Algarve, 16 de Junho, 1918).

11 A par de tais oportunidades de negócio em certos sectores, a pandemia veio impor restrições de circulação procurando proibir eventos que levassem à concentração de pessoas e animais. Exemplo desta situação foi a suspensão ou mesmo proibição das feiras de outono. O jornal o Algarve, em outubro de 1918, regista que a Feira de Faro não se realiza por causa de epidemia que está grassando, mas se "as Feiras não foram consentidas, (...) os povos, porém, que concorreram fizeram a feira do gado num campo fora da cidade" (O Algarve, 18 de outubro, p. 2).

comércio ao longo da epidemia manteve as suas lojas abertas, renovou as suas vitrines com a chegada dos produtos e novas coleções, dando sinais de continuidade da atividade, apesar da lista de falecimentos de comerciantes e empresários da praça. $O$ jornal A Capital noticia regularmente os produtos dos armazéns do Chiado, e refere a variedade de artigos que ali se pode encontrar.

13 A vida artística também dá mostra de vitalidade, todos os periódicos anunciam os concertos, recitais e espetáculos de teatro. Aliás, este parece ser um sector que fomenta as salas cheias de espectadores, local onde a pandemia (aparentemente) parecia ser esquecida.

14 Os grandes centros urbanos foram fortemente afetados pelos surtos pandémicos, mas também algumas regiões onde se verificava maior concentração de operários. A imprensa informa que, em Felgueiras, existiam muitas famílias afetadas pela gripe ; em Matosinhos, o número de casos aumentava diariamente, de tal modo que se faziam preces ao Senhor de Matosinhos para acabar com a pandemia ; em Braga, a epidemia no mês de outubro registava diariamente 14 a 15 óbitos, e no Hospital de S. Marcos adoeceu o pessoal de enfermagem sendo pedido pessoal militar para sua substituição ; em Santa Cruz do Douro, o grande número de trabalhadores que se deslocaram para as vindimas, de lá regressaram atacados pela doença... "E há já bastantes óbitos, mas somente naqueles que não têm tido assistência médica" (o Commércio do Porto, 1918, p. 1).

15 O contágio da gripe afetava trabalhadores, em todas as atividades, desde os trabalhadores agrícolas, industriais, até ao corpo clínico dos hospitais, dizimando famílias e fragilizando ainda mais os trabalhadores que se viam impedidos de obter os seus rendimentos. Na imprensa, eram constantes as listas de obituários ou a nomeação do falecimento de beneméritos, destacados industriais, empresários, ou de elementos das suas famílias.

16 O número de mortes causadas pela doença permanece por apurar com rigor, mas as últimas investigações de Rebelo-de-Andrade e Felismino (2018), apontam para 117764 vítimas mortais em Portugal, considerando todas as infeções agravadas do foro respiratório (gripe, tuberculose pulmonar, bronquite aguda e crónica, pneumonia). Segundo os estudos de Abreu e Serrão (2018), a gripe, em Portugal, "terá infetado entre um quinto e um terço dos cerca de seis milhões que então compunham a população residente (...). Atingiu especialmente a população em idade ativa, entre os 20 e os 40 anos, reforçando assim o seu impacto na economia, no mercado laboral, na fertilidade,

Laboreal, Volume $16 \mathrm{~N}^{\circ} 2$ | 2020 
na vida familiar e na organização social em geral" (p.9). Estes valores demonstram a vulnerabilidade da população face à epidemia, a falta de medidas de proteção e de serviços de saúde que atuassem estacando a proliferação dos surtos e tivessem, à época, permitido baixar os índices de letalidade das populações.

\section{BIBLIOGRAFIA}

Arquivo Municipal de Gaia/Gisa - Jornal o Commércio do Porto de 1918 e 1919.

Abreu, L., \& Serrão, J. V. (2018). Revisitar a pneumónica de 1918-1919 : introdução Dossier : Revisitar a Pneumónica de 1918-1919. Ler História, 73, 2018, 9-19.

Hemeroteca Digital - A Capital , Diário Republicano da Noite, 1918, 19. Disponível em http:// hemerotecadigital.cm-lisboa.pt/Periodicos/ACapital/ACapital.HTM. Consultado em 02- 08 de novembro de 2020 .

Hemeroteca digital - O Algarve, Semanário independe 1918-19. Disponível em http:// hemerotecadigital.cm-lisboa.pt/Periodicos/ACapital/ACapital.HTM. Consultado em 02- 08 de novembro de 2020 .

Pires, A. P. (2018). Lisboa e a grande guerra : subsistências e poder municipal, 1916-1918. In Ler História, 73, 2018. http://journals.openedition.org/lerhistoria/4267, consultado no dia 22 setembro 2020.

Rebelo-de-Andrade, H., \& Felismino, D. (2018). A pandemia de gripe de 1918-1919 : um desafio à ciência médica no princípio do século XX. In Ler História , 73, http://journals.openedition.org/ lerhistoria/4070, consultado no dia 22 setembro 2020.

Sequeira, Á. (2008). A Pneumónica, Spanish Influenza. História da Medicina, 8(1), 40-55.

\section{AUTOR}

\section{MARIA DA LUZ SAMPAIO}

HTC- FCSH Universidade Nova de Lisboa, Faculdade de Ciências Sociais e Humanas, Universidade Nova de Lisboa, Avenida de Berna 26 C, 1069-161 Lisboa

mluzsampaio@gmail.com ; mluzsampaio@fsch.unl.pt 